\title{
The Use of Probing Laser Systems in the Complex Safety Problems
}

\author{
S. A. Rudyka \\ Baltic State Technical University «VOENMEH», St.Petersburg, 190005, Russia,
}

\begin{abstract}
The paper deals with the use of probing laser systems for solving complex security problems. In particular, laser systems for remote detection of unobtrusive obstacles and for detection of vapors of hazardous substances in the air are considered. The calculations showed the efficiency of the probing laser systems for the detection of small objects, like high-voltage wires, at distances up to $800 \mathrm{~m}$. It was also shown that a compact laser probe system based on the principle of differential absorption and use of semiconductor DFB lasers, can be used to diagnose the vapors of a number of chemically hazardous substances in concentrations $1 \ldots 1000$ ppm at distances up to 1000 meters.
\end{abstract}

Keywords-sensing, laser system, integrated security, unobtrusive targets.

\section{INTRODUCTION}

In solving problems of complex safety laser systems can be effectively applied. In this paper, we consider only two areas of a wide range of possible applications of lasers: the use of lasers for remote detection of unobtrusive obstacles, which is important in the task of ensuring safety [16], and the use of lasers to detect vapors of dangerous substances in the air [8; $10]$.

Despite the different functionality of these laser systems, they have a common scheme and a similar principle of operation. The principle of operation is based on the atmospheric sounding (space sounding) by laser radiation with certain characteristics (intensity, wavelength, polarization, phase) [22]. Further, the radiation scattered by the object under study (or subject to detection) (a small obstacle, a topographic target, atmospheric molecules or aerosol particles) located in the sensing path is received $[23 ; 13 ; 3]$. Finally, an analysis of the characteristics of the scattered radiation is carried out to assess the presence of an obstacle in the sensing path or the concentration and spatial localization of chemicals in the atmosphere $[11 ; 12 ; 24]$.

Figure 1 shows the principle of operation of the probing laser system and its composition. The laser probing system includes a laser source, an optical system forming a probing beam, a receiving telescope (lens), a receiver, a control and data processing system [22]. The optical system forming the laser beam is designed to provide the required angular divergence and the diameter of the probing beam. The function of the receiving telescope is to collect the scattered signal at the maximum solid angle in order to increase the signal power and its detection by the receiver [19-21; 1].

Consider the features of laser sensing systems for the location of small objects and sensing of the atmosphere in order to detect the vapors of chemicals.

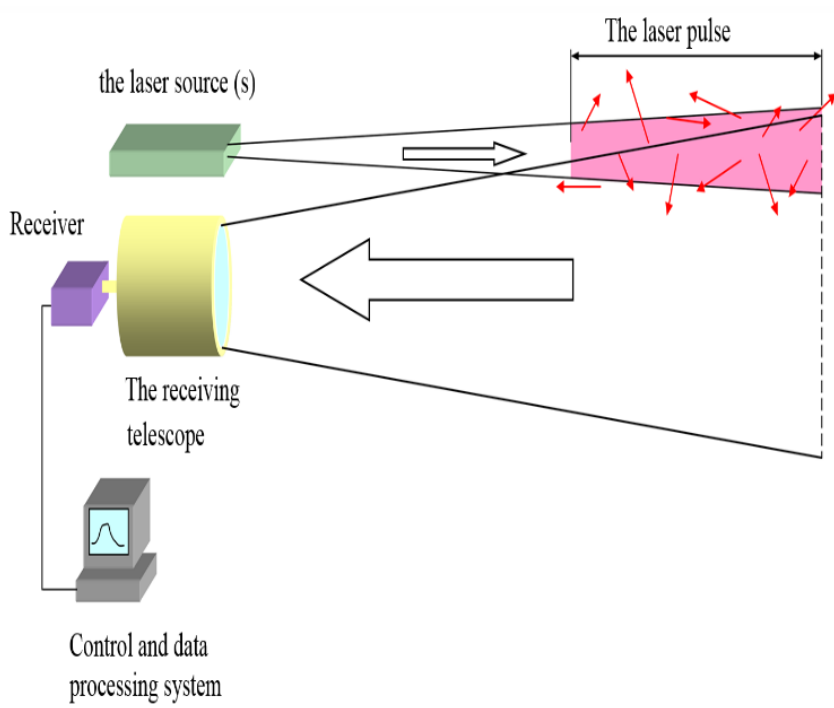

Figure 1: General scheme of the laser probing system

\subsection{Laser location of small objects}

As you know, poor visibility conditions are one of the main causes of accidents and catastrophes in the performance of low-altitude flight and takeoff and landing operations [16]. The main obstacles that pose the greatest danger when flying an aircraft at low altitude are the wires and supports of power lines and high chimneys, masts, towers, stand-alone trees, which are poorly detected by visual observation at night and in conditions of insufficient visibility.

The papers $[2 ; 16]$ describes a laser-radar module as part of a laser-television module that provides a system of situational awareness of the helicopter pilot. The laser-location module consists of a scanning system consisting of a pair of deflectors, a collimator of a pulsed laser with an alignment unit and a lens, a pulsed laser with a thermal module and a control and signal processing device built on the basis of FPGAs and including a high-speed photodetector, a signal amplifier, an analog-todigital Converter, interfaces necessary to control the modes of operation of the FPM, deflectors and a pulsed laser.

Laser pulse light source together with forming optics is used to 
create a pulse illumination of the surrounding space. Space scanning is carried out using a scanning system that deflects the laser beam and the field of view of the lens, in the focus of which is an avalanche photodiode that registers laser radiation reflected from the obstacle. The control and signal-processing device controls the operation of the pulsed laser, the scanning system and performs pre-processing of the signal (detection).

By sequentially receiving a number of pulses of light reflected from the surrounding space, the system receives a number of signals over the range. At the same time, the position sensors of each of the deflectors transmit angular coordinates, thus, the exact position of each object reflecting the laser beam is determined.

Let us estimate the possibility of detection of an unobtrusive obstacle such as high-voltage wires at a distance of 800 meters (this distance is sufficient for timely decision-making by the pilot). We define the laser beam $\Phi 0$ pr reflected from the wires and falls to avalanche diode [26]:

$F_{w}^{0}=\frac{e^{\frac{-d^{2}}{(0.5 f H)^{2}}}}{2 \sqrt{\pi}}-\frac{\rho r_{w} S_{w}}{0.5 f H^{3}} e^{-2 \mu H} W_{0}$,

where $\mu \approx \frac{3.91}{V_{m}}\left(\frac{0.55 u m}{\lambda}\right) q$,

$\mathrm{q}=0,585 V_{\mathrm{M}}^{\frac{1}{3}}$

$\mathrm{V}_{\mathrm{M}}-$ this MDV,

$\mathrm{H}$ - the distance to the wire,

$\mathrm{W}_{0}$ - laser-generated light flux,

$\mu$ - atmospheric loss factor due to aerosol and molecular attenuation (absorption and scattering),

$\lambda$ - laser wavelength,

$r_{w}$ - the radius of the wire,

$S_{w}$ - the area of the entrance pupil of the lens,

$\mathrm{f}$ - divergence of laser beam in radians,

$\mathrm{d}$ - distance from the center of the flare spot generated by the laser to the wire.

Let us assume that the distance from the wire to the center of the spot from the laser is equal to half the radius of the spot. Then the value of $e^{\frac{-d^{2}}{(f H)^{2}}}$ will be approximately 0,78

$\mathrm{f}=2 * 10-3$ radian,

$\mathrm{H}=800 \mathrm{M}$,

$\mathrm{r}_{\mathrm{w}}=5 * 10-3$ meters,

$\mathrm{S}_{\mathrm{w}}=5 * 10-3$ meters 2 (the diameter of the entrance pupil 80 $\mathrm{mm})$,

$\mathrm{W}_{0}=80 \mu \mathrm{J}$,

$\mathrm{F}_{0 \mathrm{w}}$ according to the calculations is obtained $2,9 * 10-18 \mathrm{~J}$, that at the energy of one photon at a wavelength of $1.55 \mu \mathrm{m}$ $1.28 * 10-19 \mathrm{~J}$, gives a flux of about 23 photons.
The calculation of the signal from the background on a clear sunny day at a wavelength of $1.55 \mu \mathrm{m}$ shows that it will be about 1 photon. Taking into account the noise of the receiver and the amplifying path, the signal/noise ratio under the specified conditions will be 5 , which suggests a high probability of detecting wires at a distance of up to $800 \mathrm{~m}$.

\subsection{Remote laser sensing of vapors of hazardous substances}

Laser remote sensing is a promising method for detecting, recognizing and predicting the spread of hazardous substances [6]. According to the physical principle, lidar systems are divided into: differential absorption (DIAL) lidars [7], fluorescent lidars, Raman lidars, polarization lidars, aerosol lidars $[22 ; 4 ; 5 ; 17 ; 25]$.

In recent years, interest in compact lidar systems with minimal dimensions and solving a narrowly defined range of special tasks, i.e. not being multifunctional, has become more and more active [18; 15; (Patent No. 2008134673, 25.08.2008). Prospects for the development of such lidars are due to progress in the technology of tunable semiconductor lasers (PPL). We are talking primarily about lasers with distributed feedback (distributed FeedBack - DFB lasers) and quantum cascade lasers. These lasers currently cover the spectral range from 0.6 to $12 \mu \mathrm{m}$, providing a generation power of up to hundreds of $\mathrm{mW}$. In addition, modern technology can significantly increase this power using special fibre-optic STRS amplifier [14].

The main features of compact lidars are:

- Compactness due to the use of PPL;

- Small detection range -10 ... $1000 \mathrm{~m}$;

- Use as a reflector of natural topographic target;

- Single task-detection of one, rarely several substances;

- Small dimensions of the receiving telescope $\sim 100 \mathrm{~mm}$.

We will evaluate the limiting capabilities of the dial lidar based on PPL. The absolute power $\mathrm{P}$ and the differential signal $\Delta \mathrm{P}$ at the receiver for the concentration of particles of substance $\mathrm{N}$ can be determined using Booger's law [22]:

$$
\begin{aligned}
& P \approx P_{0} \cdot \Omega \cdot \alpha \cdot(1-\eta) \\
& \Delta P=(1-\exp (-N \cdot \Delta \sigma \cdot L)) \cdot P_{0} \cdot \Omega \cdot \alpha \cdot(1-\eta)
\end{aligned}
$$

where $\mathrm{P} 0$ - the radiation power of the laser;

$\mathrm{L}$ - the optical path of the radiation to a limited extent with the vapors of the substance (in the calculations was taken equal to $1 \mathrm{~m})$; 
$\Omega=\frac{\left(\frac{\pi D^{2}}{4 \cdot R^{2}}\right)}{2 \pi}-$ geometric efficiency of the receiving system (the ratio of the solid angle inside which the signal is received to the solid angle at which the light is reflected from the diffusely scattering surface-in our case, we believe that the surface is absolutely diffuse, and the light is scattered from it into the hemisphere $2 \pi$ ), D-diameter of the receiving telescope, R-the distance to the object;

$\alpha$-diffuse surface reflectance;

$\eta$ - total value of inactive losses on the sensing path.

For modeling, electronic noise was taken into account, the main component of which was the noise of the dark current of the receiver itself. It can be determined from the value of the equivalent noise level NEP. For example, for the PIN diode of HAMATSU (Japan) G8376, the value of NEP is $8 \cdot 10-15 \mathrm{~W}$ $\cdot \mathrm{Hz}-0.5$. The bandwidth of the amplifier is $\sim 10 \mathrm{~Hz}$ power noise will be:

$$
P_{N E P}=N E P \cdot \sqrt{\Delta f}=8 \cdot 10^{-15} \cdot \sqrt{10}=2.5 \cdot 10^{-14} \mathrm{~W}
$$

The minimum detectable signal will be determined by the permissible signal-to-noise ratio SNR: $P_{\text {min }}=S N R \cdot P_{N E P}$, as distinguished by the instrument's hardware and software.

The necessary parameters for the calculation [27]:

1. The power of the $\mathrm{P} 0$ laser in the calculations was 1 $\mathrm{mW}, 10 \mathrm{~mW}$ and $100 \mathrm{~mW}$.

2. Losses in the sensing path $\eta=0.7$.

3. The concentration of $\mathrm{N}$ vapors of the diagnosed substance for calculations was taken to be $10 \mathrm{ppm}$, which is $0.27 \cdot 1021 \mathrm{~m}-3$ and $100 \mathrm{ppm}$, which is $0.27 \cdot 1022 \mathrm{~m}-3$ [9].

4. The length of the sensing path is $\mathrm{L} \sim 1 \mathrm{~m}$.

5. Typical differential absorption cross section $\Delta \sigma$ "model" substances (like ethanol) was taken equal to $1.37 \cdot 10-25 \mathrm{~m} 2$.

6. The coefficient $\alpha$ of the diffuse reflection of the topographic surface "of the reflector" was taken equal to 0.1 .

7. The scattering indicatrix was assumed to be uniform in the solid angle $2 \pi$.

8. The diameter $\mathrm{D}$ of the receiving telescope is 0.1 and $0.2 \mathrm{~m}$.

Figure 2 shows the results of lidar simulation using random topographic targets on the ground. They represent the nomograms corresponding to SNR 5 (signal/noise ratio). These nomograms show the maximum detection range of different ethanol concentrations depending on the power of the laser source.

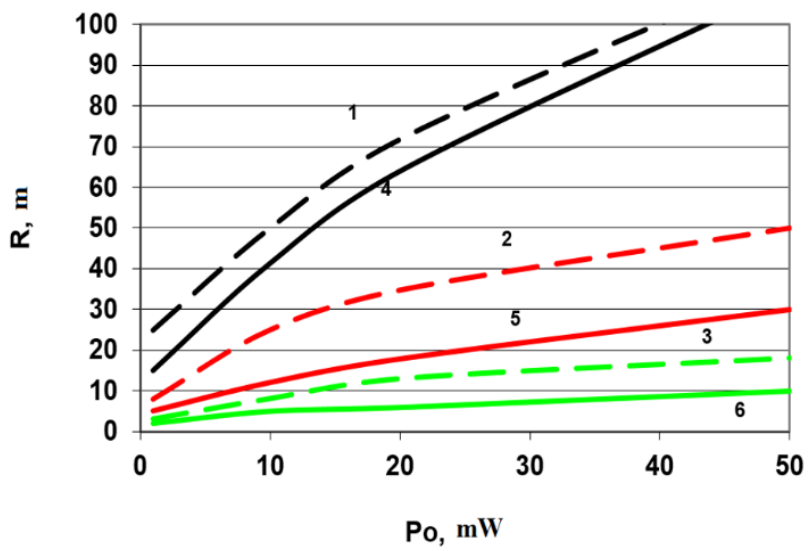

Figure 2: Dependence of the limit range of detection of ethanol vapor depending on the power of the laser source at $\alpha=0.1, \eta=0.7: 1,4-$ detectable concentrations $100 \mathrm{ppm}, 2,5-$ 10 ppm, 3, $6-1$ ppm; 1, 2, 3-D=0.2 m; 4, 5, 6-D=0.1 m.

In general, the numerical simulation showed that the use of a compact lidar for the diagnostics of hazardous substances in the open atmosphere at concentrations at the level of $0.01 \ldots 1 \mathrm{ppm}$, the detection distance can reach hundred meters (when using the random topographic targets) and kilometers (by using special retroreflectors-reflectors).

\section{CONCLUSION}

Probing laser systems are an effective tool in providing comprehensive security. In particular, the calculations showed the efficiency of the probing laser systems for the detection of small objects that pose a threat to flight safety, at distances up to $800 \mathrm{~m}$. It was also shown that a compact laser probe system based on the principle of differential absorption and using semiconductor lasers, can be used to diagnose the vapors of a number of chemically hazardous substances in concentrations $1 . .1000 \mathrm{ppm}$ at distances up to 1000 meters.

\section{CONFLICT OF INTEREST}

The authors confirm that there is no conflict of interest to declare for this publication

\section{ACKNOWLEDGEMENT}

The work was carried out in accordance with the decree of the Government of the Russian Federation from 09.04.2010 № 218 (PROJECT 218) in the framework of R\&D, executing with the financial support of the Ministry of education and science of the Russian Federation (agreement № 074-11-2018025 from 13.07.2018). Work is performed in lead R\&D performer organization: Federal State Budgetary Educational Institution of Higher Professional Education BSTU "VOENMEH" named after D.F. Ustinov. 
International Journal of Engineering Research and Technology. ISSN 0974-3154, Volume 13, Number 11 (2020), pp. $3705-3709$

(C) International Research Publication House. https://dx.doi.org/10.37624/IJERT/13.11.2020.3705-3709

\section{REFERENCES}

[1] Belko, V. O., Petrenya, Y. K., Andreev, A. M., Kosteliov, A. M., Roitgarz, M. B. (2019). Numerical simulation of discharge activity in HV rotating machine insulation. Paper presented at the Proceedings of the 2019 IEEE Conference of Russian Young Researchers in Electrical and Electronic Engineering, ElConRus 2019, 800-802. doi:10.1109/EIConRus.2019.8657272

[2] Belsky A., Josan N., Grebenshchikov V., Kargaev A., Brondz D., Gorbachev K., Vorobiev D. (2013). Laser location systems to improve the safety of helicopters. Photonics(5(41)), pp. 66-75.

[3] Bisyarin, M. A., Kotov, O. I., Hartog, A. H., Liokumovich, L. B., Ushakov, N. A. (2018). Rayleigh backscattered radiation produced by an arbitrary incident mode in multimode optical fibers. Applied Optics, 57(22), 6534-6544. doi:10.1364/AO.57.006534

[4] Boreisho A. S., A. A. (25.08.2008). Patent No. 2008134673.

[5] Boreisho A. S., M. A. Konyaev , A.V. Morozov, A. V. Pikulik, A. V. Savin, A. V., Trilis, S. J. Chakir, N. And. Boiko, Yu. N. Vlasov, S. P. Nikitaev, A. V. Rozhnov. (2005). Mobile multi-wave lidar systems. Quantum electronics, 35(12), pp. 1167-1178.

[6] Boreysho A.S., V.A.Volodenko, N.A.Gryaznov, E.R.Malamed, Yu.N.Mendov, V.L.Moshkov, S.M.Pantaleev, A.V.Pankratiev, A.E.Finagin, S.Ya.Chakchir. (2004). Mobile lidar complex for ecological monitoring of the atmosphere. Proc. of SPIE., 5479.

[7] Burtseva E. V., Druzhinin, S. L., Pakhomova N. And. Strakhov S. Yu. (2006). The analysis of techniques of processing a LIDAR signal based on the algo-rithms of correlation and regression analysis. Proc. of SPIE, 6594.

[8] Byer. (1975). Remote air pollution measurement. Opt. and Quantum Elect., 7, pp. 147-177.

[9] Gorelik, D. O., Konopelko L. A. (1992). Monitoring of air pollution and emission sources. Moscow: Publication of standards.

[10] Hinckley, E. E. (1979). Laser monitoring of the atmosphere. Moscow: Mir.

[11] Inochkin, F. M., Pozzi, P., Bezzubik, V. V., Belashenkov, N. R. (2017). Increasing the space-time product of super-resolution structured illumination microscopy by means of two-pattern illumination. Paper presented at the Proceedings of SPIE - the International Society for Optical Engineering, 10333. doi:10.1117/12.2271835

[12] Kniazkov, A. V., Harisov, R. I. (2016). Comparison of methods for determining the coherence of semiconductor laser light based on interference fringe contrast and speckle pattern morphology. Journal of Optical Technology (A Translation of Opticheskii
Zhurnal), 83(5), 309-312. doi:10.1364/JOT.83.000309

[13] Korolev, A. N., Lukin, A. Y., Polishchuk, G. S. (2017). Use of information redundancy in optical digital measurement systems with 2D sensor. Measurement Techniques, 60(3), 242-247. doi:10.1007/s11018-0171180-9

[14] Makarov N.S., (n.d.). http://www.ict.edu.ru/ft/001836/sbornik6_4_4_8_2.pdf.

[15] Malyugin S., T.Moskalev, A.Nadezhdinskii, D.Namestnikov, Ya.Ponurovskii, Yu.Shapovalov, D.Stavrovskii, I.Vyazov, V.Zaslavskii. (n.d.). Ethanol vapor detection limited by diode laser frequency quantum noise. Retrieved from http://dls.nsc.gpi.ru/eng/conf/TDLS2005/Posters/B13.p df

[16] Matveev S. A., Byzov A. N., Bystrov S. Yu., Garmash V. N., S. I. Isaenko, D. M. Korobochkin, Yu. V. Petrov, Rudyk S. A., Strakhov S. Yu., Syrtsev A. N. (n.d.). Helicopter complex of information support of flight safety and carrying out search and rescue operations. Bulletin of KRSU, 18(9), pp. 60-64.

[17] Mejeris. (1987). Laser remote sensing. Moscow: Mir.

[18] Nadezhdinskii A., A. Berezin, Yu. Bugoslavsky, O. Ershov, V. Kutnyak. (1999). Application of near-IR diode lasers for measurement of ethanol vapor. Spectrochimica Acta, 55, pp. 2049-2055.

[19] Privalov, V. E., Shemanin, V. G. (2017). Estimation of the error of lidar measurements of atmospheric radionuclide concentrations. Measurement Techniques, 1-6. doi:10.1007/s11018-017-1301-5

[20] Privalov, V. E., Shemanin, V. G. (2017). Lidar system for monitoring radioactive contamination of atmospheric air. Journal of Optical Technology (A Translation of Opticheskii Zhurnal), 84(5), 289-293. doi:10.1364/JOT.84.000289

[21] Privalov, V. E., Shemanin, V. G. (2018). Hydrogen sulfide molecules lidar sensing in the atmosphere. Optical Memory and Neural Networks (Information Optics), 27(2), 120-131. doi:10.3103/S1060992X18020091

[22] Rozhdestvin, e. V. (2002). Optoelectronic systems of environmental monitoring of the natural environment. Moscow: MGTU im. N. Eh.Bauman.

[23] Rud, V. Y., Rud, Y. V., Terukov, E. I. (2016). Polarization studies of the photoelectric properties of II-IV-V 2 -semiconductor-compound-electrolyte systems. Journal of Optical Technology (A Translation of Opticheskii Zhurnal), 83(5), 275-278. doi:10.1364/JOT.83.000275

[24] Safronov, A. A., Vasil'eva, O. B., Dudnik, Y. D., Kuznetsov, V. E., Shiryaev, V. N., Subbotin, D. I., Obraztsov, N.V., Surov, A.V., Popov, V. E. (2018). Use of alternating-current plasma torch for processing potentially hazardous substances. High Energy 
International Journal of Engineering Research and Technology. ISSN 0974-3154, Volume 13, Number 11 (2020), pp. 3705-3709

(C) International Research Publication House. https://dx.doi.org/10.37624/IJERT/13.11.2020.3705-3709

Chemistry, 52(4), 319-323.

doi:10.1134/S0018143918040136

[25] Savin A.V., S.Yu.Strakhov, M.A.Konyaev, A.V.Trilis. (2006). Lidar system for atmospheric turbulence measurement with Mersen telescope. Proc. of SPIE, 6160 .

[26] Sharov S.N.. (2018). Information channels of control systems. Sankt-Petersburg: BGTU "VOENMECH".

[27] Strakhov. S.Yu. (26-30.09.2009). Advantages laser technologies. Optical Methods and Systems for Distance and Contact Dangerous Matters Detection. 